\title{
From 2000 years of Ganoderma lucidum to recent developments in nutraceuticals
}

\author{
Karen S. Bishop ${ }^{\mathrm{a}, *}$, Chi H.J. Kao ${ }^{\mathrm{b}}$, Yuanye Xu ${ }^{\mathrm{b}}$, Marcus P. Glucina ${ }^{\mathrm{c}}$, R. Russell M. Paterson ${ }^{\mathrm{d}}$, \\ Lynnette R. Ferguson ${ }^{\mathrm{a}, \mathrm{b}}$ \\ ${ }^{a}$ Auckland Cancer Society Research Centre, Faculty of Medical and Health Sciences, The University of Auckland, Private Bag 92019, Auckland 1142, New Zealand \\ ${ }^{\mathrm{b}}$ Discipline of Nutrition, Faculty of Medical and Health Sciences, The University of Auckland, Private Bag 92019, Auckland 1142, New Zealand \\ ${ }^{\mathrm{c}}$ NZFOCUS (NZ) Ltd., Auckland, New Zealand \\ ${ }^{\mathrm{d}}$ IBB-Centre of Biological Engineering, University of Minho, Campus de Gualtar, 4710-057 Braga, Portugal
}

\section{A R T I C L E I N F O}

\section{Article history:}

Available online 17 March 2015

\section{Keywords:}

Medicinal mushrooms

Ganoderma lucidum

Ganodermataceae

Lingzhi

Taxonomy

History

Health benefits

Nutraceuticals

\begin{abstract}
A B S T R A C T
Medicinal mushrooms have been used for centuries as nutraceuticals to improve health and to treat numerous chronic and infectious diseases. One such mushroom is Ganoderma lucidum, commonly known as Lingzhi, a species revered as a medicinal mushroom for treating assorted diseases and prolonging life. The fungus is found in diverse locations, and this may have contributed to confusion regarding the correct taxonomic classification of the genus Ganoderma. G. lucidum was first used to name a specimen found in England and thereafter was naively applied to a different Ganoderma species found in Asia, commonly known as Chinese Lingzhi. Despite the taxonomic confusion, which has largely been uncorrected, the popularity of Lingzhi has escalated across the globe. The current taxonomic situation is now discussed accurately in this Special Issue on Ganoderma. Today it is a multi-billion dollar industry wherein Lingzhi is cultivated or collected from the wild and consumed as a tea, in alcoholic beverages, and as a nutraceutical to confer numerous health benefits. Consumption of nutraceuticals has grown in popularity, and it is becoming increasingly important that active ingredients be identified and that suppliers make substantiated health claims about their products. The objective of this article is to present a review of G. lucidum over the past 2000 years from prized ancient "herbal" remedy to its use in nutraceuticals and to the establishment of a 2.5 billion $\$$ (US) industry.
\end{abstract}

(c) 2015 Elsevier Ltd. All rights reserved.

\section{Introduction to medicinal mushrooms as nutraceuticals}

The word "nutraceutical" was first coined by Stephen Defelice when he combined the terms "nutrition" and "pharmaceutical" in 1989 (Brower, 1998). From that point on there has been much controversy regarding whether nutraceuticals should be considered as foods or medicines, and whether they should be regulated. One particular definition describes a nutraceutical as a product that is isolated from a food, and believed to have a benefit to health or prevention of chronic disease (Health Canada, 1998). However,

Abbreviations: AIDS, acquired immunodeficiency syndrome; BCE, before the common era; BPH, benign prostatic hyperplasia; FD\&C Act, Food, Drug, and Cosmetics Act; GA, ganoderic acid; HIV, Human Immunodeficiency Virus; HPLC, high performance liquid chromatography; ITS, internal transcribed spacer; MMP, Matrix Metalloproteinase; Mt-SSU, mitochondrial small-subunit; ROS, reactive oxygen species; RPBI, RNA polymerase I subunit; RPBII, RNA polymerase II subunit; TCM, traditional Chinese medicine; TEF1- $\alpha$, translational elongation factor 1-alpha.

* Corresponding author. Tel.: +649 9234471; fax: +6493035962.

E-mail address: k.bishop@auckland.ac.nz (K.S. Bishop). the term "nutraceutical" is not globally accepted and has no regulatory definition (Gautam, 2013). Broadly speaking, nutraceuticals encompass functional foods, the active components of functional foods, dietary supplements and medicinal foods (Brower, 1998) as well as foods containing probiotics (Chaturvedi et al., 2011), and this is how the term is interpreted from the point of view of this article. The following definition will be understood for probiotics: "live microorganisms that, when administered in adequate amounts, confer a health benefit on the host" (FAO/ WHO, 2002).

Numerous mushrooms have for centuries been revered for their miracle cures and general health promoting benefits (Ferreira et al., 2010). Predominantly in Asian countries, various mushroom species are grown in the wild and used as nutraceuticals, despite much of the evidence for benefit being anecdotal or obtained from animal model experiments. Nonetheless, there is evidence of potential benefit from using various mushroom extracts with respect to anti-bacterial, anti-inflammatory, anti-viral, antiatherosclerotic, anti-diabetic and anti-cancer activity (De Silva 
et al., 2012; Wasser, 2011). Historically, a number of effective and widely used drugs were obtained from plant sources, and in order to promote wide use of these drugs in modern times, the key active ingredients were identified and synthesised. An example of a drug that is widely used for its medicinal properties and whose design was based on medicinal properties of an active ingredient from a plant source is Aspirin. Aspirin is the trade name for acetylsalicylic acid, a prodrug, which was inspired by anecdotal evidence of the medicinal properties of salicylic acid. Salicylic acid is the active ingredient originally obtained from salicylate rich plants such as willow (Raskin, 1992) and used for centuries before the mechanism of action was identified. Many feel that medicinal mushrooms are underutilised and have huge potential for providing health benefit (Jenkin, 2014). However, some regard the active ingredients of mushrooms too complex to synthesise (as claimed by Chris Kilham in (Jenkin, 2014)) or is it that we have not delved sufficiently deeply into the treasure chest of nutraceutical-fungal biochemistry? Regardless of whether evidence is anecdotal or clinically proven, nutraceuticals are flooding onto the market. However, with growing competition and awareness, consumers are becoming increasingly discerning and seeking proof for claims made, thus making it necessary to identify the active ingredients in order to report on the quantity present in the nutraceutical being purchased. In addition, scientific evidence is often essential to appease mounting regulatory requirements when making health claims with respect to nutraceuticals (Chaturvedi et al., 2011). For these reasons, amongst others, it is important to support health claims made about a nutraceutical product with scientific evidence, rather than making loose statements regarding the superiority of one Ganoderma lucidum based product over another.

There are a number of fungal species that are traditionally used as nutraceuticals around the globe (Ajith and Janardhanan, 2007; Ferreira et al., 2010; Wasser, 2011). These include G. lucidum (Lingzhi), Ophiocordyceps (previously Cordyceps) species (Paterson, 2008), Grifola frondosa (Hen of the woods/Maitake), Lentinula edodes (Shiitake), Piptoporus betulinus (Birch polypore/ bracket), Inonotus obliquus (Chaga), and Agaricus subrufescens (Almond mushroom), amongst numerous others (De Silva et al., 2012; Wasser, 2011). However, Lingzhi is probably the most widely known and highly revered medicinal mushroom amongst populations living in Asia.

\section{Historical usage of G. lucidum: the "Mushroom of Immortality"}

The objective of this article is to present a review of G. lucidum over the past 2000 years from prized ancient "herbal" remedy to its use in nutraceuticals and to the establishment of a 2.5 billion \$ (US) industry (Li et al., 2013). Worldwide, the species name G. lucidum has been applied to Chinese Lingzhi (Wang et al., 2012b) which is well known as a basidiomycete and has been referred to as the "Mushroom of Immortality" (Li et al., 2013). Lingzhi has been widely used in China for medicinal purposes since before the common era (BCE). This fungus has been predominantly used by Asian populations to not only improve wellbeing and general health (Shiao, 2003), but has also been used alone or alongside Western chemotherapy treatment to inhibit cancer or to assist with side-effects (Gordan et al., 2011; Papadopoulos et al., 2007; Sliva, 2003). In addition, its use has become increasingly widespread to prevent obesity; reduce cholesterol; for the maintenance of gut health; reduction of hypertension; control of diabetes and the stimulation of probiotics, amongst others (Jin et al., 2012; Paterson, 2006; Sanodiya et al., 2009).

In ancient times, Lingzhi was grown in the wild and consumed only by the very wealthy, whereas nowadays a large proportion is cultivated and is more widely consumed across socioeconomic groups as an alternative to, or alongside, modern medicine (Leung et al., 2003; Zhao et al., 2011). As greater emphasis is placed on prevention of chronic diseases, indicated by the recent press release of the International Agency for Research on Cancer to coincide with World Cancer Day (WHO, 2014), more people may begin seeking nutraceuticals (including probiotics) to support their health. The statement made by Hippocrates, "Let food be your medicine and medicine be your food" (Sparks, 2006) harmonises with the current perspective: classical views on dietetics have persisted to the modern day.

Today Lingzhi is consumed as a nutraceutical (in the form of a soup/tea or other concoctions) by predominantly Asian populations as a means of improving well-being and health. This practice may have its roots in the Shen Nong Ben Cao Jing, known in the West as "The Divine Farmer's Materia Medica", a highly regarded pharmacopoeia text dating back to the Qin dynasty (221-206 BCE) (Yang, 1998). In this text, six types of "zhi" (characteristics/ qualities) are described, the qing, chi, huang, bai, hei and zi zhi. All are described as being able "to prevent senility, prolong life as to make one immortal" (Yang, 1998). Differences in usage varied between each type, for example, the "bai zhi" (white Ganoderma) was purported to boost the lung qi (energy), whereas "hei zhi" (black Ganoderma) boosted kidney qi and sharpened hearing (Yang, 1998). With these descriptions, it is evident why Lingzhi has been considered a fungus of special capability, a "plant of immortality" (Stuart, 1911). However, it is also thought that the reputation of Lingzhi may have arisen by virtue of its rarity and its use by privileged members of Chinese society, rather than solely due to anecdotal evidence (Wachtel-Galor et al., 2011).

To set the historical context of using Lingzhi to treat diseases, it is worth considering that over the past 2000 years, the role of Lingzhi has been depicted in Chinese literature and art. Several hundreds of years after the original descriptions of Lingzhi in the Shen Nong Ben Cao Jing, the poet Jiang Yan (444-505) wrote about the character for Lingzhi as to "indicate the speaker's proper virtue", attributing the overarching respect for this fungus to other poets of his time (Williams, 2007). Nearly a millennium thereafter, the silversmith Zhu Bishan (c. 1300) crafted his earliest known work, a Lingzhi shaped drinking cup (no longer extant) (Wilson, 1994). With the progress of another five centuries, Lingzhi was portrayed in the art of the Jiajing period (1522-1566) (Wan, 2007). A cover box displayed at the Palace Museum in Beijing depicts Lingzhi with vapours emanating to form auspicious Chinese characters, linking with the belief that Lingzhi could confer immortality, pursued by the Jiajing emperor who incessantly consumed Lingzhi preparations (Wan, 2007). With a background spanning more than two millennia, steeped in the culture of the Chinese people, Lingzhi has found fame and popularity. The current market for extracts and preparations continues to expand. However, despite the growing popularity of Lingzhi nutraceuticals, the question still remains as to whether there is an evidence base for pharmacological effects of active substances present in the fungus.

The continued growth in usage of Lingzhi necessitates, amongst other things, the correct identification of species and active ingredients. From a nutraceutical perspective, this also entails the establishment of safe doses and quality control. These elements have been considered herein.

\section{Taxonomy}

Lingzhi has huge economic value predominantly due to its medicinal and cultural importance. Confusion with respect to species identification could lead not only to complications with commercial claims, patents and publications, but may also result in the incorrect treatment of diseases, conflicting results with 
respect to drug development, and complications with respect to mushroom toxicity (Wasser, 2011). For these reasons, it is important to be unambiguous about which fungus is being referred to in the literature and when purchasing in the market. These nomenclatural issues are now extensively covered in this Special Issue on Ganoderma with an up-to-date revision of the correct name (Zhou et al., 2015) which should be referred to.

G. lucidum was first described by William Curtis in 1781 based on material grown in England (cited in Wang et al., 2012b). The first scientific record of $G$. lucidum from China was made by Teng in 1934 when he incorrectly identified a Lingzhi specimen as G. lucidum (cited in (Wang et al., 2012b)). Further confusion arose when chlamydospore production was used to distinguish Ganoderma tsugae from G. lucidum. Like G. tsugae, European G. lucidum does not produce ovoid chlamydospores in culture, whereas G. lucidum grown in the USA does (Moncalvo et al., 1995).

Work by Hseu (1990) showed that G. lucidum and G. tsugae represent two biological species that had recently diverged (Hseu in (Moncalvo et al., 1995)). Prior to this, Adaskaveg and Glibertson (1986) reported that North American G. lucidum and European Ganoderma resinaceum belonged to the same species, yet Moncalvo et al. (1995) found no evidence of this (Moncalvo et al., 1995). Ryvarden (1991) (cited in (Moncalvo et al., 1995)) observed high phenotypic plasticity in Ganoderma and concluded that strong speciation has not yet been achieved. Variable morphology and recent divergence is supported by Moncalvo et al. (1995).

Many believe that all taxa can be reliably distinguished using culture characteristics, where conditions can be tightly controlled, but that these characteristics are not always useful in defining monophyletic lineages (Moncalvo et al., 1995). However, culture characteristics alone may be insufficient to conclusively assign all specimens to the correct species. Before the advent of modern molecular biology, there was much taxonomic confusion regarding certain Ganoderma species (Moncalvo et al., 1995), and even today, clarity does not prevail. Sequencing data from the internal transcribed spacer (ITS) region of ribosomal DNA, as well as from the divergent domain D2 region of the large ribosomal subunit gene, were compared across the Ganoderma genus to the corresponding positions 425-648 of Saccharomyces cerevisiae, and sequences from these regions were used to cluster specimens (Moncalvo et al., 1995). In addition, Cao et al. (2012) used the mitochondrial small-subunit ribosomal DNA (mt-SSU), DNA-directed RNA polymerase II subunit (RPB2), and translational elongation factor 1-alpha (TEF1- $\alpha$ ) sequences to study the phylogenetic relationships amongst G. tsugae, "true" G. lucidum and "Lingzhi". Cao et al. (2012), conclude that G. tsugae grown on conifers in north eastern China is conspecific with European G. lucidum; that G. lucidum and "Lingzhi" are different species; and that there is strong support for renaming G. tsugae from Japan and Taiwan as "Lingzhi".

In addition, work carried out by Wang et al. (2012b) was used to support the conclusion that Chinese Lingzhi was conspecific with Ganoderma sichuanense and was a different species from G. lucidum found in the UK. That is, the fungus named Ganoderma lucidum in tropical Asia is actually Ganoderma multipileum (Wang et al., 2009). Similar to the model proposed by Moncalvo et al. (1995), these conclusions were drawn based on the analyses of three sequenced regions, namely ITS (non-functional RNA), intergenic spacers (i.e. non-transcribed DNA) and RPB2, as well as morphological evidence (Wang et al., 2012b). However, a consensus has not been reached regarding renaming of incorrectly named species. In order to assist with the clarification of the species, Hawksworth (2005) proposed that a new name be introduced for the European "G. lucidum" and that the well-known Chinese Lingzhi, maintain the name G. lucidum, while Cao et al. (2012) have proposed that the original Eurasian G. lucidum retain its name and that the phylogenetically distinct Lingzhi, predominantly from East Asia, be renamed Ganoderma lingzhi and referred to as Lingzhi. The latter appears to have been partially adopted (Fatmawati et al., 2013; Sun et al., 2014).

In addition to classification based on morphological characters and molecular phylogenetic analyses, chemistry may also be applied to assist with the delineation of closely related species. It is well known that G. lucidum is rich in polysaccharides and triterpenoids, and it is possible that both the polysaccharide and triterpenoid profiles could be used to differentiate between various Ganoderma species providing clarity with respect to classification. Despite the difficulties associated with the separation and identification of Ganoderma polysaccharides, Sun et al. (2014) recently established an high performance liquid chromatography (HPLC) based methodology to characterise species within the genus Ganoderma using polysaccharide fingerprint profiling. Polysaccharide fingerprint profiles were used to differentiate between G. lucidum and Ganoderma sinense, and differences were also noted between different strains, different growth conditions and different geographic origins (Sun et al., 2014).

In contrast to Ganoderma polysaccharides, a greater volume of work has been published on the use of triterpenes, particularly ganoderic acids (GAs), to differentiate between species. In a study reported in 1999, Chen et al. (1999) were able to use an analysis of triterpenoids to differentiate between G. tsugae and G. lucidum. However, although the three G. tsugae strains tested presented with similar spectral profiles, the three G. lucidum strains tested had profiles that were both very different from those generated from G. tsugae strains, and from each other. This is consistent with the molecular phylogenetic data previously mentioned and is supported by the strength of the various clades of the most parsimonious tree presented by Cao et al. (2012). Chen and Chen (2003) went on to develop the spectral profiles further by purifying and identifying additional GAs using reversed-phase HPLC and semipreparative HPLC. Thereafter, Liu et al. (2011) used a sensitive and selective liquid chromatography-tandem mass spectrometry method for the simultaneous determination of five GAs in G. lucidum, G. sinense and Ganoderma applanatum fruiting bodies.

Care must be taken when applying and developing chemotaxic criteria as the type and quantity of the informative compound, for example triterpenes, can be influenced by the growth stage at which the product is harvested, which part of the fungus is harvested, as well as the growth or environmental conditions (Liu et al., 2012). Although chemotaxonomy may not be useful to allow for the definitive delineation of the Ganoderma species at this time, it will allow rough separation and perhaps more importantly, facilitate the quality control of Ganoderma products.

\section{Modern uses of G. lucidum and proof of effect}

In traditional Chinese medicine (TCM), G. lucidum is purported to support a vast array of health benefits, and modern studies involving animal models and molecular-based research techniques have been used to demonstrate numerous pharmacological effects supporting these claims (Jong and Birmingham, 1992; Sanodiya et al., 2009; Wachtel-Galor et al., 2011). More specifically, G. lucidum has been shown to have potential in the treatment of modern diseases such as cancer, diabetes, and Human Immunodeficiency Virus (HIV) (Sanodiya et al., 2009).

Despite the many reported medicinal properties of G. lucidum, the mechanisms of action have remained poorly defined. With improvements in modern research techniques, detailed investigations into these mechanisms of action in which G. lucidum can exert the observed health benefits are becoming increasingly possible. In addition, better separation and purification techniques have allowed for the isolation and identification of some of the active components in G. lucidum. Modern researches have focused 
on two primary active components, namely polysaccharides and triterpenes.

\subsection{Polysaccharides}

In addition to triterpenes, polysaccharides from G. lucidum are also believed to confer a health benefit. Polysaccharides are long chain sugar molecules joined together by glycosidic bonds. Various types of polysaccharides, with molecular weights ranging from $4 \times 10^{5}$ to $1 \times 10^{6}$ Daltons have been identified in the fruiting body and mycelia of $G$. lucidum (Sanodiya et al., 2009). Irrespective of the molecular weight of the polysaccharides, a number of them have a positive impact on reducing cancer progression (Sanodiya et al., 2009).

Structural analysis shows that polysaccharides of G. lucidum are mostly high molecular weight heteropolymers (Fig. 1) (Chan et al., 2007). Glucose forms the major component of the sugar molecule together with xylose, mannose, galactose, and fucose in different conformations. Different types of polysaccharides from this fungus, with different branching conformations and solubility, can induce different immune responses with varying immune potencies (Chan et al., 2007). In addition to the soluble polysaccharides, $G$. lucidum also consists of a matrix of the polysaccharide, chitin, which is largely indigestible and is partly responsible for the physical hardness of the mushroom (Upton, 2000). Despite evidence being presented on the effect of individual triterpenes in in vivo and in vitro experiments, polysaccharide-rich extracts from this fungus seem to have undergone limited testing, with no results presented on the effect of individual heteropolymers. This may be due to the difficulties associated with isolation and detection of such heteropolymers.

\subsubsection{Neurological effects}

In addition to triterpenes, the polysaccharides found in G. lucidum are also believed to confer a neurological benefit. Although little scientific evidence exists and further work is required to support this claim, G. lucidum has been used for its analgesic and muscle relaxing properties since ancient times (Zhang et al., 2011). On the other hand, Matsuzaki et al. (2013) have demonstrated that the water extract (which therefore contains polysaccharides) of G. lucidum exhibits an anti-depressant-like effect and reduces anxiety-type behaviour in rats, a finding which is yet to be replicated in studies involving human subjects.

\subsubsection{Immune-modulation}

G. lucidum polysaccharides have been demonstrated to modulate and improve immune function in both human studies and mouse models (Gao et al., 2003; Wang et al., 2007). Administration of<smiles>[R]C(CC(C)C(=O)O)CC(C)C1CC([R2])C2(C)C1=C1C([R])CC3C(C)(C)C([R])CCC3(C)C1C([R])C2[R]</smiles>

Fig. 2. The core molecular structure of ganoderic acids, a subtype of triterpenes that contain four cyclic and two linear isoprenes. The different chemical compounds in $\mathrm{R}$ groups $\left(R_{1}-R_{6}\right)$ determine ganoderic acid subtype and its biochemical properties (figure adapted from (Liu et al., 2012)).

G. lucidum extracts resulted in increased secretion of cytokines from immune cells which leads to increased cellular activity and survival of immune cells related to innate (macrophages) and adaptive immunity (lymphocytes) (Bach et al., 2009; Mantovani and Sica, 2010). These polysaccharides have also been found to improve anti-tumour immune response by promoting the activity of natural killer cells and cytotoxic T-lymphocytes (Chang, 2004; Pan et al., 2013). In addition, the polysaccharides from this fungus are shown to enhance expression of major histocompatibility complex in a melanoma cell line, which improves antigen presentation thus promoting viral and cancer immunity (Sun et al., 2011).

\subsection{Triterpenes}

Triterpenes are one of the main biologically active groups of compounds that contribute to the various health benefits of G. lucidum (Shi et al., 2010; Wachtel-Galor et al., 2011). Triterpenes are a subtype of terpenes composed of six isoprene units. The isoprenes in triterpenes may form linear chains, or ringlike structures. GAs are a subtype of triterpenes with four cyclic and two linear isoprenes (Liu et al., 2012). There are over 140 species of GAs that have been identified from G. lucidum (Yue et al., 2010). The core molecular structure of GA is shown in Fig. 2. The various types of GAs are characterised by different R-groups.

Triterpenes are low molecular weight compounds which can target cellular processes such as apoptosis, cell cycle regulation and angiogenesis through direct interaction with molecular targets (Ferreira et al., 2010; Froufe et al., 2013). Results from a number of studies have been published wherein a specific triterpene or a mixture of triterpenes, isolated from G. lucidum, have been identified, together with an association with various health benefits. These associations will be discussed in the following subsections.

\subsubsection{Anti-oxidative effect}

Free radicals and reactive oxygen species (ROS) are generated as by-products of metabolic processes involving redox enzymes and

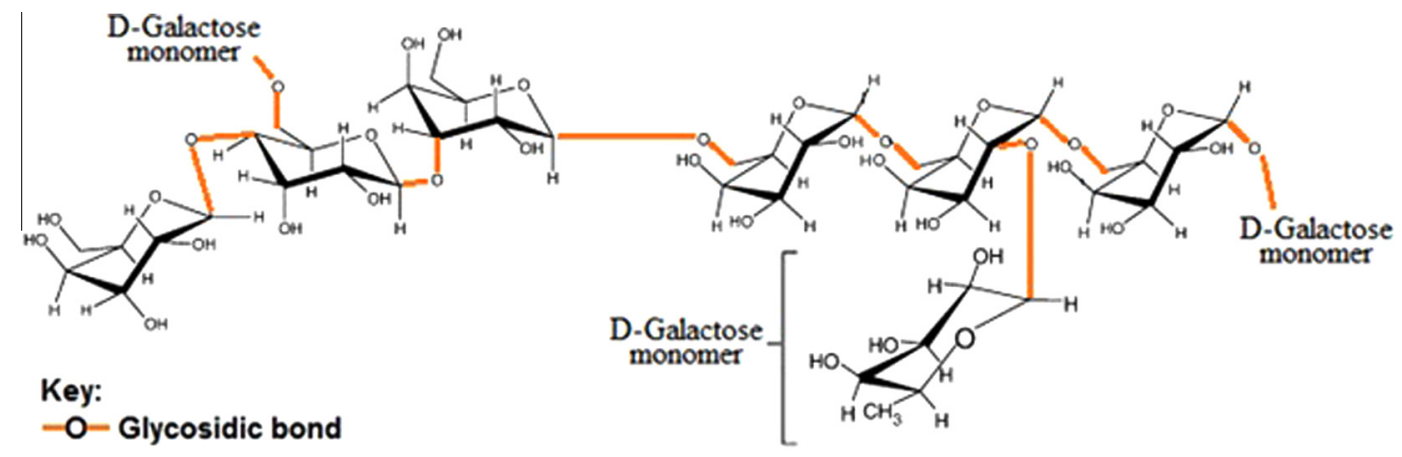

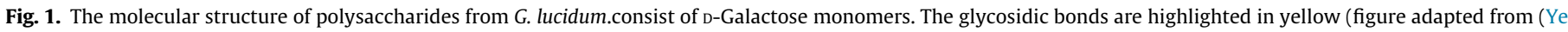
et al., 2010)). (For interpretation of the references to colour in this figure legend, the reader is referred to the web version of this article.) 
bioenergetics electron transfer, as well as in response to exposure to some exogenous chemicals (Alphay, 2014; Yue et al., 2006). ROS and free radicals can damage cells through oxidation, and long-term accumulation of such damage causes aging and various age-associated diseases (Lobo et al., 2010). Studies have been used to show that G. lucidum increases the activity of super oxide dismutase and catalase which are enzymes involved in removing harmful ROS (Ajith et al., 2009; Cherian et al., 2009; Smina et al., 2011). In addition, administration of triterpenes to mice increased the activity of antioxidant enzymes, and reduced radiation-induced oxidative DNA damage in mice splenocytes (Stojkovic et al., 2014).

\subsubsection{Anti-cancer and cytotoxic activities}

G. lucidum has been shown to have anti-cancer activity in in vivo (mouse model) and cytotoxic effects in in vitro (cancer cell lines) studies (Wachtel-Galor et al., 2011). Various types of extracts from G. lucidum have shown carcinostatic effects in a wide variety of cancer cell lines, including breast, pancreas, lung, colon, skin, and prostate (Wachtel-Galor et al., 2011). There are many mechanisms by which the G. lucidum extracts exhibit anti-cancer activities. These include direct inhibition of cell proliferation through cancer-specific cell cycle arrest and apoptosis (Fukuzawa et al., 2008; Jedinak et al., 2011; Tang et al., 2006; Wu et al., 2012). In addition, a number of researchers have shown that treatment of cancer cells with G. lucidum extracts can lead to down-regulation of cell cycle-associated proteins resulting in cell cycle arrest (Jedinak et al., 2011; Sliva et al., 2012; WHO, 2014; Wu et al., 2013). Apoptosis of cancer cell lines was also observed after treatment with G. lucidum triterpenes and Fukuzawa et al. (2008) and Tang et al. (2006) demonstrated that apoptosis is triggered by the increase of pro-apoptotic proteins and decrease of anti-apoptotic proteins. In a study by Liu et al. (2012) the structural activity relationship of GA-DM (Fig. 3) was investigated and it was found to inhibit the proliferation of the aggressive human prostate cancer cell line PC3. GA-DM (1) and various analogues were tested for growth inhibition in PC3 and it was found that the carbonyl group at C-3 is essential for growth inhibition (Fig. 3) (Liu et al., 2012). Furthermore, Liu et al. (2012) also found that an analogue of GA-DM (2), with a methyl group at C-26, can more effectively penetrate the membrane and is subsequently metabolised to GA-DM by PC3. In addition to evidence obtained regarding the cytotoxicity of G. lucidum, Thyagarajan et al. (2010) showed that a G. lucidum triterpene extract inhibited tumour growth in a mouse model with xenograft human colon cancer (Thyagarajan et al., 2010). Subsequently, De Silva et al. (2012) demonstrated that a triterpene extract of G. lucidum given orally, significantly reduced colon tumour formation and inflammation in mice exposed to carcinogens.

\subsubsection{Anti-metastatic activities}

Cancer metastasis is a complex process by which cancer cells dissociate from the primary tumour and invade other tissues forming secondary tumours (Leber and Efferth, 2009). Cancer metastasis, when left untreated, dramatically reduces the rate of cure and survival (Leber and Efferth, 2009). Matrix
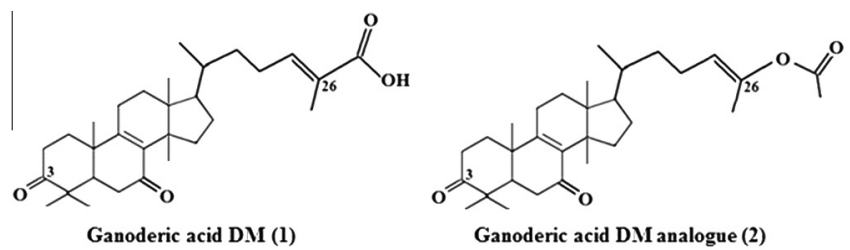

Fig. 3. Ganoderic acid DM (1) and its analogue (2) (figure adapted from Liu et al., 2012).
Metalloproteinases (MMP) are a family of proteins that degrade the extracellular matrix and can promote cancer metastasis (Bielawski et al., 2008; Liu et al., 2012; Shuman Moss et al., 2012). A number of researchers have shown that GA-Me (3) (Fig. 4) and -T (4) (Fig. 4) suppressed the invasion of LLC and HCT-116 metastatic cancer cells via inhibition of pre-metastatic gene expression such as urokinase-type plasminogen activator and MMP-2 and -9 (Chen et al., 2008; Chen and Zhong, 2011; Zong et al., 2003).

\subsubsection{Anti-HIV activity}

HIV is a highly infectious virus affecting an estimated 35 million people worldwide (Paydary et al., 2013). HIV induces a lethal and incurable condition known as acquired immunodeficiency syndrome (AIDS). Current treatment strategies for HIV involve delaying the progression of the disease into AIDS (Paydary et al., 2013). Research on the effects of G. lucidum on HIV has identified various compounds that exhibit inhibitory effects. For example, triterpenoids in G. lucidum have been shown to have anti-HIV-1 protease activity (Min et al., 1998). In one of the earliest studies investigating this topic, El-Mekkawy et al. (1998) assayed thirteen compounds isolated from G. lucidum. Several of these compounds showed anti-HIV-1 activity, including GA-A (5) (Fig. 5), which exhibited inhibitory activity against HIV-1 proteases. Although triterpenoids appear to be the major class of compounds with anti-HIV effects, G. lucidum also contains laccases which may inhibit HIV-1 reverse transcriptase (Wang and $\mathrm{Ng}$, 2006). It is clear that much more research must be performed to ascertain a mechanistic basis for G. lucidum isolates as anti-HIV agents, including determination of the structure-activity relationship between triterpenes from G. lucidum and HIV proteases, amongst others.

\subsubsection{Effect on lower urinary tract symptoms in men}

Lower urinary tract symptoms are often secondary to benign prostatic hyperplasia (BPH), the latter found commonly amongst older men (Liu et al., 2007). In two clinical trials carried out in Japan by Noguchi et al. (2008a, b) on men with slight or moderate lower urinary tract symptoms (but no suspicion of prostate cancer), a dose of $6 \mathrm{mg}$ from a G. lucidum ethanol extract was deemed to be safe and effective. In addition, the $6 \mathrm{mg}$ dose of the aforementioned extract was shown to improve the International Prostate

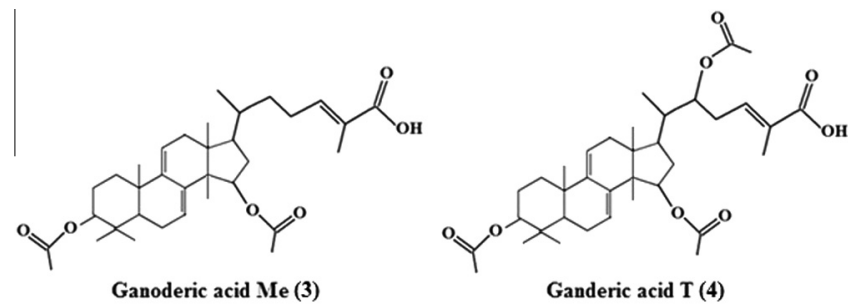

Fig. 4. Ganoderic acid Me (3) and ganoderic acid T (4) (figure adapted from Tang et al., 2006).

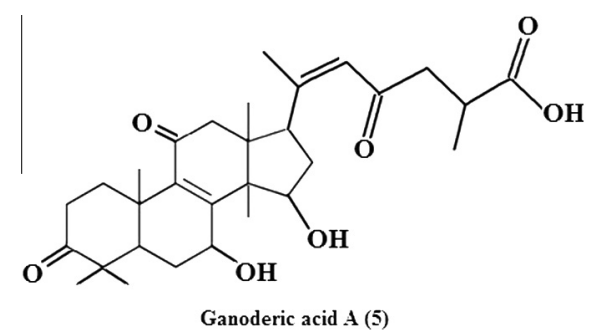

Fig. 5. Ganoderic acid A (5) (figure adapted from (El-Mekkawy et al., 1998)). 
Symptom Score in men enrolled in both studies, although prostate volume appeared to be unaffected (Noguchi et al., 2008b). Suppression effects of prostatic growth by G. lucidum might be partly due to its ability to inhibit $5 \alpha$-reductase, which is over-expressed in BPH tissues (Liu et al., 2007). The enzyme $5 \alpha$-reductase converts testosterone to the more potent form dihydrotestosterone which promotes growth of prostate cells by stimulating the androgen receptor (Liu et al., 2007).

\subsubsection{Neuro-protective effect}

G. lucidum is believed to have a neuro-protective effect and this notion is supported by work carried out by Zhang et al. (2011) and Zhao et al. (2011), wherein a mixture of triterpenoid compounds in G. lucidum, including methyl GA-A (6), methyl GA-B (7), GA-S1 (8), and GA-TQ (9) (Fig. 6), promoted neuronal survival and reduced fatigue (Zhang et al., 2011; Zhao et al., 2012). In addition, the potential use of this fungus for the treatment of neurological diseases has also been examined. It was shown that long-term consumption of G. lucidum can decrease the progression of Alzheimer's disease (Lai et al., 2008; Zhou et al., 2012). This observed neuroprotective effect is achieved by promotion of neuritogenesis and reduction of senescence of the neurons (Ling-Sing Seow et al., 2013).

\subsubsection{Biotechnological production of G. lucidum triterpenes}

Due to the potential medicinal properties of G. lucidum, there has been an increase in the commercial demand for this fungus. Various cultivation methods have been developed to increase yield of the active compounds in G. lucidum, in particular its triterpenes.

However, artificial cultivation of G. lucidum is time-consuming and the level of active compounds within the fungus are difficult to control (Zhong and Tang, 2004). Submerged fermentation has been used as an alternate method for the efficient production of GAs (Xu et al., 2010). By manipulating the fermentation conditions such as medium components, oxygen supply, and $\mathrm{pH}$, the production of GAs in the mycelium can be enhanced. It was found that the addition of sodium and manganese can lead to a 2.8 and a 2.2-fold increase in the GA content, respectively (Xu et al., 2013, 2014). The increased GA production is likely due to the activation of calcineurin signalling pathway induced by calcium/sodium exchange (Xu et al., 2013; Xu and Zhong, 2012). Furthermore, production of GAs can be improved by deliberate overexpression of specific genes in G. lucidum (Xu et al., 2012). Overexpression of 3-hydroxy-3-methylglutaryl CoA reductase, a key enzyme in GA synthesis, has led to a 2-fold increase in total GA produced (Xu et al., 2012). In addition, the level of specific GAs can be increased using additional chemical conversion processes to convert the analogue impurities to the desired compound (Wang et al., 2012a).
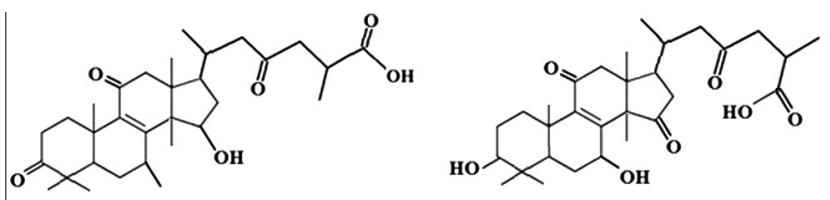

Methyl ganoderic acid A (6)

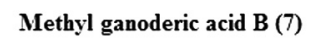

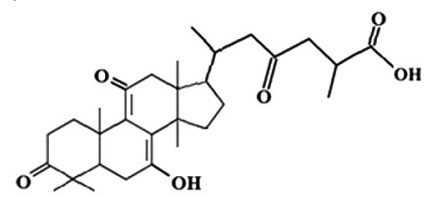

Ganoderic acid Sl (8)

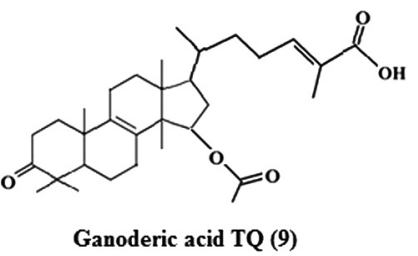

Fig. 6. Chemical structures of methyl ganoderic acid A (6), methyl ganoderic acid B (7), ganoderic acid S1 (8), and ganoderic acid TQ (9) (figure adapted from Zhang et al., 2011).
More specifically, it was found that using hydrolysis and acetylation, the amount of GA-T (4) can be increased 4-fold by converting the GA-T analogues to GA-T (4) (Wang et al., 2012a).

The production of $G$. lucidum through enhanced cultivation methods is increasing. By developing enhanced growth conditions wherein the concentration of the biologically active ingredients is increased may help increase health benefit. Both increased production and enhanced benefit may help meet and promote demand for this fungus and enable further development of products containing G. lucidum within the nutraceutical industry.

\section{Applications as nutraceuticals}

In order to consider G. lucidum as a nutraceutical, it is important to first verify whether the criteria, outlined in the definition, have been met. As previously mentioned, there is little consensus on the meaning of the term "nutraceutical". However, there are various criteria that have been proposed including whether the product is isolated from foods; whether the isolated product be sold in a medicinal form; and whether the proposed nutraceutical has been shown to protect against chronic disease or show some physiological benefit (Health Canada, 1998). The criterion that it be an isolate or purified form, has been fulfilled: there are many examples of $G$. lucidum products being sold in such forms, for example "GanoPoly", an aqueous polysaccharide fraction isolated with patented methods (Gao et al., 2005). In Section 4 of this review, the current status of the evidence base for physiological benefits that G. lucidum may provide, has been outlined. This supports the latter criterion of the Health Canada definition of "nutraceutical", although this must be validated by experts in each of the countries for which G. lucidum may be marketed under the "nutraceutical" label. The U.S. Food, Drug, and Cosmetics Act (FD\&C Act) does not recognise the term "nutraceutical". However, the concepts behind the Health Canada proposal are seen in the definitions provided for "food" and "drug" in the FD\&C Act (U.S. Food and Drug Administration, 2010). Although there is some debate as to whether $G$. lucidum can be regarded as a food, mostly due to its fibrous nature (5.9\%), it does predominantly consist of water (90\%), carbohydrate $(2,8 \%)$, fat $(0.5 \%)$ and protein $(0.8 \%)$ (Mau et al., 2001), and thus, like all other foods, consists of macronutrients.

Lingzhi products may be sold as prescription drugs in some Asian countries, although internationally most are advertised as dietary supplements (Lai et al., 2004). With approximately 5000 tons of G. lucidum produced annually (based on a 2002 estimate), at a valuation of more than $\$ 2.5$ billion US dollars, the economic impact of these products is globally significant (Lai et al., 2004; Li et al., 2013). There are a large number of G. lucidum products available, varying in terms of the part of the fungus processed, the method of extraction, as well as mode of delivery, whether it be in the form of tonics, pills or powders (Lai et al., 2004). As an example, one particular product is marketed as a cardiovascular care formula, in the form of capsules (Encore, 2014). The list of benefits the manufacturers lay claim to includes support of "normal blood pressure", "healthy condition of our heart and blood vessels", and to "maintain peripheral circulation", amongst others (Encore, 2014). Another product comes in the form of a mixed tea, including other medicinal mushrooms, the description noting that it "supports the body's immune system, improves vitality and promotes digestion" (Alphay, 2014). In both cases, labelling of the product is limited to health benefit claims about structure, function or wellbeing (Alphay, 2014; Encore, 2014; Lai et al., 2004).

Both pharmaceutical products and nutraceuticals may have adverse effects and drug interactions as the biologically active components present in the product may exert effects 
through the presence of active substances already present in the body. In terms of interactions with other drugs, G. lucidum extracts appear to enhance the sensitivity of epithelial ovarian cancer cells to cisplatin in vitro (Zhao et al., 2011) for example. Similarly, the polysaccharide fraction 3 of $G$. lucidum synergises with cisplatin and arsenic trioxide to inhibit the proliferation of resistant urothelial carcinoma cells (Huang et al., 2010). There are plenty of studies that can be used to elucidate the beneficial drug interactions that G. lucidum may provide, synergism and additive effects such as those already described. However, studies on the toxicity and adverse effects of G. lucidum are, to date, much less common. A 2008 in vitro study showed that Lingzhi extracts have the potential to cause toxicity when exposed to cells at levels higher than those concentrations required for stimulatory effects, with significant reduction in cell viability observed in some cell lines (Gill and Rieder, 2008).

Lingzhi carries with it a long history of usage for various medicinal purposes in TCM. This may influence its perception as a nutraceutical, as many people believe in the effects claimed by TCM practitioners. For example, the usage of G. lucidum for its An-Shen effect (tranquilising) was only recently supported with evidence from an animal model study (Cui et al., 2012) yet has been used for centuries for its tranquilising effect. This study showed that the administration of G. lucidum extract increased total sleep time and non-rapid eye movement significantly in rats, with a possible mechanism related to TNF- $\alpha$ (Cui et al., 2012). More evidence of this sort is required to appropriately support TCM claims about the health benefits of $G$. lucidum products.

In addition to evidence based health claims, it is also important to identify the bioavailability of the biologically active components of G. lucidum after oral administration, and very little has been published in this area. Although single compounds can mediate a biological effect, nutraceuticals often act through the synergistic activity of multiple metabolites. It is important to gain a better understanding of the bioavailability of the active components in this mushroom under different conditions so as to ensure robust study designs and to maximise consumer benefit.

Low bioavailability of TCMs is not uncommon after oral administration of single compounds (Cheng et al., 2013) and this creates challenges with respect to identification and characterisation of the biologically active compounds (Adamec et al., 2009), which are more easily identified when administered individually. A number of researchers have developed methods to aid with assessment of the bioavailability of various GAs, whilst others have studied factors that may influence bioavailability (Adamec et al., 2009; Cheng et al., 2013; Gao et al., 2004; Qi et al., 2012; Teekachunhatean et al., 2012; Zhang et al., 2009).

The number of commercially available reference standards limits the number of triterpenes that can be readily analysed. For this reason Qi et al. (2012) developed a liquid chromatography - mass spectrometry method to identify the most effective triterpenes found in G. lucidum with the intention of using these results to subsequently identify samples via HPLC, and thus avoid the need for reference standards. Prior to this, Adamec et al. (2009) successfully used Group Specific Internal Standard Technology (better known as GSIST) to identify and compare the GA content in different G. lucidum extracts, as well as the time profiles of GAs-A (5) and $-\mathrm{H}$ (10), and ganoderiol F (GF) (11) (Fig. 7) in plasma from rats after receiving a gastric gavage (Adamec et al., 2009). In an effort to improve bioavailability, Cheng et al. (2013) assessed the bioavailability of GA-D (12), in lipid nanoparticles and in solution (Cheng et al., 2013). The time to reach peak plasma concentration was 36 min for the GA-D nanoparticles versus 2 hrs for the GA-D (12) in solution (Cheng et al., 2013). Likewise, the absolute bioavailability (bioavailability is commonly abbreviated in formulae as " $F$ ") of the GA-D increased from 0.22 in solution to 0.70 in nanoparticles (Cheng et al., 2013). Earlier, Zhang et al. (2009) found that the
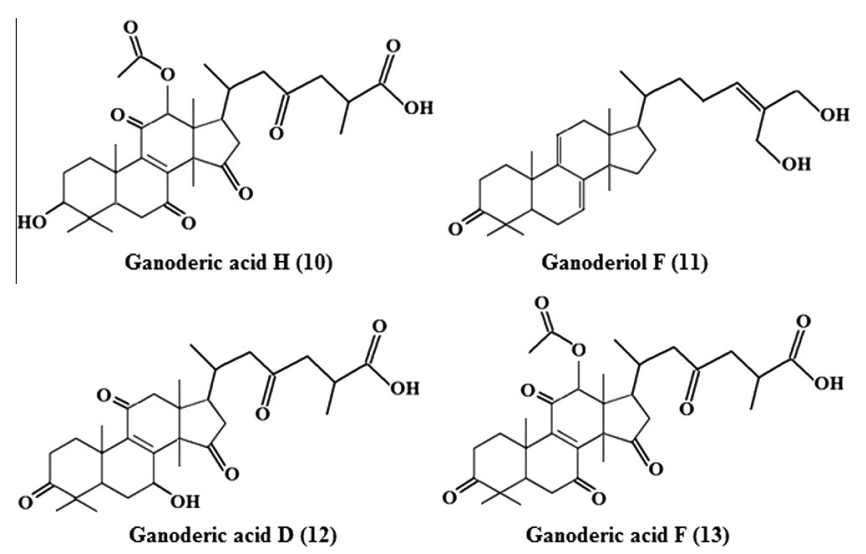

Fig. 7. Chemical structures of ganoderic acid $\mathrm{H}(\mathbf{1 0})$, ganoderiol $\mathrm{F}(\mathbf{1 1})$, ganoderic acid D (12), and ganoderic acid F (13).

absolute bioavailability of GF (11) in rats was $F=0.015$ after oral administration following fasting (Zhang et al., 2009). Absolute bioavailability refers to the bioavailability of the compound administered orally, relative to the bioavailability of the same compound administered intravenously (Balant, 1991). The bioavailability of the latter is assumed to be 100\% (Balant, 1991).

Proximity of administration to food consumption is believed to influence bioavailability and for this reason Teekachunhatean et al. (2012) assessed the timing of food consumption on the pharmacokinetics of GA-A (5) and ganoderic acid F (GA-F) (13) (Fig. 7) after consumption of a water based extract of G. lucidum in human males. Consistent with other studies, it was found that time to peak concentration for both GA-A (5) and GA-F (13) were approximately $30 \mathrm{~min}$ in the fasting state. However, if a meal was consumed prior to oral dosing with these GAs, then time to peak concentration increased and peak concentration decreased such that GA-F (13) concentrations were below the lower limit of quantification $(0.50 \mathrm{ng} / \mathrm{mL})$ (Teekachunhatean et al., 2012). Clearly variation exists amongst the GAs with respect to bioavailability and experiments need to be carefully controlled.

Considering G. lucidum as a nutraceutical, its current position is that of a product requiring additional research and analysis to elucidate matters of safety, adverse effects, drug interactions, bioavailability, support for TCM claims, regional differences, species differences, as well as the environmental conditions under which it is grown (wild versus cultivated).

\section{The future of G. lucidum}

Nutraceuticals are a growing health care industry worldwide, and as the occurrence of chronic diseases and awareness of preventative strategies increase, so too will demand for nutraceuticals. More and more people are seeking to solve their own health related problems by using natural products to prevent or ameliorate disease. However, as awareness of the need for evidence based claims rises, so too will requirements of regulatory bodies and customers.

Lingzhi, owing to its lengthy history as a medicinal mushroom, has attained an almost divine status in its usage to promote health. Despite this, for Lingzhi to reach its economic and medicinal potential a number of challenges need to be addressed: clarity regarding the taxonomy of Lingzhi needs to be provided; further work on the identification of active ingredients should be carried out and this will enable the active ingredients within nutraceutical products to be measured; dose ranges need to be established for both the safe and beneficial dose of active ingredients for each disease type; 
growth conditions may need to be optimised in order to increase production, maximise the active ingredients and to ensure purity; and clinical trials will need to be carried out to provide convincing evidence of benefit against both chronic and infectious diseases. As Chaturvedi et al. (2011) suggest, perhaps we are moving towards an era where "a nutraceutical a day keeps the doctor away".

\section{Acknowledgements}

Funding from NZ Focus to BK, MPG and LRF is acknowledged. YX was funded by a Phyllis Paykel Memorial Scholarship, and KSB and LRF were supported by the Auckland Cancer Society Research Centre.

\section{References}

Adamec, J., Jannasch, A., Dudhgaonkar, S., Jedinak, A., Sedlak, M., Sliva, D., 2009. Development of a new method for improved identification and relative quantification of unknown metabolites in complex samples: determination of a triterpenoid metabolic fingerprint for the in situ characterization of Ganoderma bioactive compounds. J. Sep. Sci. 32, 4052-4058.

Ajith, T., Janardhanan, K., 2007. Indian medicinal mushrooms as a source of antioxidant and antitumor agents. J. Clin. Biochem. Nutr. 40, 157-162.

Ajith, T.A., Sudheesh, N.P., Roshny, D., Abishek, G., Janardhanan, K.K., 2009. Effect of Ganoderma lucidum on the activities of mitochondrial dehydrogenases and complex I and II of electron transport chain in the brain of aged rats. Exp. Gerontol. 44, 219-223.

Alphay, 2014. Lingzhi - Royal Blend Herbal Tea. <http://www.alphayglobal.com/ Products/Alphay CafeBlends/LingzhiTea> Accessed 23 January 2014.

Bach, J.P., Deuster, O., Balzer-Geldsetzer, M., Meyer, B., Dodel, R., Bacher, M., 2009. The role of macrophage inhibitory factor in tumorigenesis and central nervous system tumors. Cancer 115, 2031-2040.

Balant, L.P., 1991. Is there a need for more precise definitions of bioavailability? Eur. J. Clin. Pharmacol. 40, 123-126.

Bielawski, K., Bielawska, A., Slodownik, T., Bolkun-Skomicka, U., Muszyñska, A., 2008. Proline-linked nitrosoureas as prolidase-convertible prodrugs in human breast cancer cells. Pharmacol. Rep. 60, 171.

Brower, V., 1998. Nutraceuticals: poised for a healthy slice of the healthcare market? Nat. Biotechnol. 16, 728-731.

Cao, Y., Wu, S.-H., Dai, Y.-C., 2012. Species clarification of the prize medicinal Ganoderma mushroom "Lingzhi”. Fungal Divers. 56, 49-62.

Chan, W., Law, H., Lin, Z., Lau, Y., Chan, G., 2007. Response of human dendritic cells to different immunomodulatory polysaccharides derived from mushroom and barley. Int. Immunol. 19, 891-899.

Chang, S.T., 2004. Mushrooms cultivation, nutritional value, medicinal effect, and environmental impact. CRC Press, Boca Raton, Fla, Boca Raton, Fla.

Chaturvedi, S., Sharma, P.K., Garg, V.K., Bansal, M., 2011. Role of nutraceuticals in health promotion. Int. J. Pharm. Technol. Res. 4, 5.

Chen, D.-H., Shiou, W.-Y., Wang, K.-C., Huang, S.-Y., Shie, Y.-T., Tsai, C.-M., Shie, J.-F., Chen, K.-D., 1999. Chemotaxonomy of triterpenoid pattern of HPLC of Ganoderma lucidum and Ganoderma tsugae. J. Chin. Chem. Soc. 46, 47-51.

Chen, D.H., Chen, K.D., 2003. Determination of ganoderic acids in triterpenoid constituents of Ganoderma tsugae. J. Food Drug Anal. 11, 195-201.

Chen, N.H., Liu, J.W., Zhong, J.J., 2008. Ganoderic acid Me inhibits tumor invasion through down-regulating matrix metalloproteinases 2/9 gene expression. J. Pharmacol. Sci. 108, 212-216.

Chen, N.H., Zhong, J.J., 2011. P53 is important for the anti-invasion of ganoderic acid $\mathrm{T}$ in human carcinoma cells. Phytomedicine 18, 719-725.

Cheng, C.-R., Yang, M., Guan, S.-H., Wu, X.-H., Pang, X.-Y., Wang, Y., Yang, Y., Ding, J., Guo, D.-A., 2013. Pharmacokinetics of ganoderic acid D and its main metabolite by liquid chromatography-tandem mass spectrometry. J. Chromatogr. B 930, 1 6.

Cherian, E., Sudheesh, N.P., Janardhanan, K.K., Patani, G., 2009. Free-radical scavenging and mitochondrial antioxidant activities of Reishi-Ganoderma lucidum (Curt: Fr) P. Karst and Arogyapacha-Trichopus zeylanicus Gaertn extracts. J. Basic Clin. Physiol. Pharmacol. 20, 289-307.

Cui, X.-Y., Cui, S.-Y., Zhang, J., Wang, Z.-J., Yu, B., Sheng, Z.-F., Zhang, X.-Q., Zhang, Y.H., 2012. Extract of Ganoderma lucidum prolongs sleep time in rats. J. Ethnopharmacol. 139, 796-800.

De Silva, D., Rapior, S., Fons, F., Bahkali, A., Hyde, K., 2012. Medicinal mushrooms in supportive cancer therapies: an approach to anti-cancer effects and putative mechanisms of action. Fungal Divers. 55, 1-35.

El-Mekkawy, S., Meselhy, M.R., Nakamura, N., Tezuka, Y., Hattori, M., Kakiuchi, N., Shimotohno, K., Kawahata, T., Otake, T., 1998. Anti-HIV-1 and anti-HIV-1protease substances from Ganoderma lucidum. Phytochemistry 49, 1651-1657.

Encore, 2014. Products. 2014. <http://www.alpha-group.co.nz> Accessed: 23 January 2014.

FAO/WHO, 2002. Guidelines for the evalutaion of probiotics in food. Report of a Joint FAO/WHO Working Group on Drafting Guidelines fo the Evalutaion of Probiotics in Food. Ontario, Canada.
Fatmawati, S., Kondo, R., Shimizu, K., 2013. Structure-activity relationships of lanostane-type triterpenoids from Ganoderma lingzhi as $\alpha$-glucosidase inhibitors. Bioorg. Med. Chem. Lett. 23, 5900-5903.

Ferreira, I., Vaz, J., Vasconcelos, M.H., Martins, A., 2010. Compounds from wild mushrooms with antitumor potential. Anti-Canc. Agents Med. 10, 424-436.

Froufe, H.J.C., Abreu, R.M.V., Ferreira, I.C.F.R., 2013. Virtual screening of low molecular weight mushrooms compounds as potential Mdm2 inhibitors. J. Enzyme Inhib. Med. Chem. 28, 569-575.

Fukuzawa, M., Yamaguchi, R., Hide, I., Chen, Z., Hirai, Y., Sugimoto, A., Yasuhara, T., Nakata, Y., 2008. Possible involvement of long chain fatty acids in the spores of Ganoderma lucidum (Reishi Houshi) to its anti-tumor activity. Biol. Pharm. Bull. 31, 1933-1937.

Gao, J.J., Nakamura, N., Min, B.S., Hirakawa, A., Zuo, F., Hattori, M., 2004. Quantitative determination of bitter principles in specimens of Ganoderma lucidum using high-performance liquid chromatography and its application to the evaluation of ganoderma products. Chem. Pharm. Bull. 52, 688-695.

Gao, Y., Zhou, S., Jiang, W., Huang, M., Dai, X., 2003. Effects of ganopoly (a Ganoderma lucidum polysaccharide extract) on the immune functions in advanced-stage cancer patients. Immunol. Invest. 32, 201-215.

Gao, Y.G., Chan, H., Tang, E., Xu, W., Yang, A., Huang, H., Lan, M., Li, J., Duan, X., Xu, W.C., Zhou, S., 2005. Antitumor activity and underlying mechanisms of Ganopoly, the refined polysaccharides extracted from Ganoderma lucidum, in mice. Immunol. Invest. 34, 171-198.

Gautam, S.P., 2013. Nutraceuticals: a boom to medical industry. Res. Gate Pharm. Sci. 2, 1-8.

Gill, S.K., Rieder, M.J., 2008. Toxicity of a traditional Chinese medicine, Ganoderma lucidum, in children with cancer. Can. J. Clin. Pharmacol. 15, e275-e285.

Gordan, J.D., Chay, W.-Y., Kelley, R.K., Ko, A.H., Choo, S.-P., Venook, A.P., 2011. And what other medications are you taking? J. Clin. Oncol. 29, e288-e291.

Hawksworth, D.L., 2005. Reflections on changing names and related nomenclatural issues in edible and medicinal mushrooms. Int. J. Med. Mushr. 7, 29-38.

Health Canada, 1998. Policy paper - nutraceuticals/functional foods and health claims on foods. 2014. Health Canada, Canada. <http://www.hc-sc.gc.ca/fn-an/ label-etiquet/claims-reclam/nutra-funct_foods-nutra-fonct_aliment-eng.php> Accessed 23 January 2014

Huang, C.-Y., Chen, J.Y.-F., Wu, J.-E., Pu, Y.-S., Liu, G.-Y., Pan, M.-H., Huang, Y.-T., Huang, A.M., Hwang, C.-C., Chung, S.-J., 2010. Ling-Zhi polysaccharides potentiate cytotoxic effects of anticancer drugs against drug-resistant urothelial carcinoma cells. J. Agric. Food Chem. 58, 8798-8805

Jedinak, A., Thyagarajan-Sahu, A., Jiang, J., Sliva, D., 2011. Ganodermanontriol, a lanostanoid triterpene from Ganoderma lucidum, suppresses growth of colon cancer cells through ss-catenin signaling. Int. J. Oncol. 38, 761-767.

Jenkin, M., 2014. Could mushrooms be the cure for cancer?, The Guardian, vol. 2 Mar, UK.

Jin, X., Ruiz Beguerie, J., Sze, D.M., Chan, G.C., 2012. Ganoderma lucidum (Reishi mushroom) for cancer treatment. Cochrane Db. Syst. Rev. 6, CD007731.

Jong, S.C., Birmingham, J.M., 1992. Medicinal benefits of the mushroom Ganoderma. Adv. Appl. Microbiol. 37, 101-134.

Lai, C.S., Yu, M.S., Yuen, W.H., So, K.F., Zee, S.Y., Chang, R.C., 2008. Antagonizing betaamyloid peptide neurotoxicity of the anti-aging fungus Ganoderma lucidum. Brain Res. 1190, 215-224.

Lai, T., Gao, Y., Zhou, S., 2004. Global marketing of medicinal Ling Zhi mushroom Ganoderma lucidum (W.Curt.:Fr.) Lloyd (Aphyllophoromycetideae) products and safety concerns. Int. J. Med. Mushr. 6, 6.

Leber, M.F., Efferth, T., 2009. Molecular principles of cancer invasion and metastasis. Int. J. Oncol. 34, 881-895.

Leung, P.C., Xue, C., Cheng, Y.C., 2003. A Comprehensive Guide to Chinese Medicine. World Scientific Publisher.

Li, J., Zhang, J., Chen, H., Chen, X.Q., Lan, L., Liu, C., 2013. Complete mitochondrial genome of the medicinal mushroom Ganoderma lucidum. PLoS ONE 8, 111.

Ling-Sing Seow, S., Naidu, M., David, P., Wong, K.H., Sabaratnam, V., 2013. Potentiation of neuritogenic activity of medicinal mushrooms in rat pheochromocytoma cells. BMC Complement. Altern. Med. 13, 157.

Liu, J., Kurashiki, K., Fukuta, A., Kaneko, S., Suimi, Y., Shimizu, K., Kondo, R., 2012 Quantitative determination of the representative triterpenoids in the extracts of Ganoderma lucidum with different growth stages using high-performance liquid chromatography for evaluation of their $5 \alpha$-reductase inhibitory properties. Food Chem. 133, 1034-1038.

Liu, J., Shimizu, K., Konishi, F., Noda, K., Kumamoto, S., Kurashiki, K., Kondo, R., 2007. Anti-androgenic activities of the triterpenoids fraction of Ganoderma lucidum. Food Chem. 100, 1691-1696.

Liu, Y., Liu, Y., Qiu, F., Di, X., 2011. Sensitive and selective liquid chromatographytandem mass spectrometry method for the determination of five ganoderic acids in Ganoderma lucidum and its related species. J. Pharm. Biomed. Anal. 54, 717-721.

Lobo, V., Patil, A., Phatak, A., Chandra, N., 2010. Free radicals, antioxidants and functional foods: impact on human health. Pharmacogn. Rev. 4, 118-126.

Mantovani, A., Sica, A., 2010. Macrophages, innate immunity and cancer: balance, tolerance, and diversity. Curr. Opin. Immunol. 22, 231-237.

Matsuzaki, H., Shimizu, Y., Iwata, N., Kamiuchi, S., Suzuki, F., Iizuka, H., Hibino, Y., Okazaki, M., 2013. Antidepressant-like effects of a water-soluble extract from the culture medium of Ganoderma lucidum mycelia in rats. BMC Complement. Altern. Med. 13, 370.

Mau, J.-L., Lin, H.-C., Chen, C.-C., 2001. Non-volatile components of several medicinal mushrooms. Food Res. Int. 34, 521-526. 
Min, B.S., Nakamura, N., Miyashiro, H., Bae, K.W., Hattori, M., 1998. Triterpenes from the spores of Ganoderma lucidum and their inhibitory activity against HIV-1 protease. Chem. Pharm. Bull. 46, 1607-1612.

Moncalvo, J.-M., Wang, H.-F., Hseu, R.-S., 1995. Gene phylogeny of the Ganoderma lucidum complex based on ribosomal DNA sequences. Comparison with traditional taxonomic characters. Mycol. Res. 99, 1489-1499.

Noguchi, M., Kakuma, T., Tomiyasu, K., Kurita, Y., Kukihara, H., Konishi, F., Kumamoto, S., Shimizu, K., Kondo, R., Matsuoka, K., 2008a. Effect of an extract of Ganoderma lucidum in men with lower urinary tract symptoms: a doubleblind, placebo-controlled randomized and dose-ranging study. Asian J. Androl. 10, 651-658.

Noguchi, M., Kakuma, T. Tomiyasu, K., Yamada, A., Itoh, K., Konishi, F., Kumamoto, S., Shimizu, K., Kondo, R., Matsuoka, K., 2008b. Randomized clinical trial of an ethanol extract of Ganoderma lucidum in men with lower urinary tract symptoms. Asian J. Androl. 10, 777-785.

Pan, K., Jiang, Q., Liu, G., Miao, X., Zhong, D., 2013. Optimization extraction of Ganoderma lucidum polysaccharides and its immunity and antioxidant activities. Int. J. Biol. Macromol. 55, 301-306.

Papadopoulos, I., Guo, F., Lees, S., Ridge, M., 2007. An exploration of the meanings and experiences of cancer of Chinese people living and working in London. Eur. J. Cancer Care 16, 424-432.

Paterson, R.R., 2006. Ganoderma - a therapeutic fungal biofactory. Phytochemistry 67, 1985-2001.

Paterson, R.R.M., 2008. Cordyceps - a traditional Chinese medicine and another fungal therapeutic biofactory? Phytochemistry 69, 1469-1495.

Paydary, K., Khaghani, P., Emamzadeh-Fard, S., Alinaghi, S.A., Baesi, K., 2013. The emergence of drug resistant HIV variants and novel anti-retroviral therapy. Asian Pac. J. Trop. Biomed. 3, 515-522.

Qi, Y., Zhao, L., Sun, H.H., 2012. Development of a rapid and confirmatory method to identify ganoderic acids in Ganoderma mushrooms. Front. Pharmacol. 3, 1-7.

Raskin, I., 1992. Salicylate, a new plant hormone. Plant Physiol. 99, 799-803.

Sanodiya, B.S., Thakur, G.S., Baghel, R.K., Prasad, G.B., Bisen, P.S., 2009. Ganoderma lucidum: a potent pharmacological macrofungus. Curr. Pharm. Biotechnol. 10, 717-742.

Shi, L., Ren, A., Mu, D., Zhao, M., 2010. Current progress in the study on biosynthesis and regulation of ganoderic acids. Appl. Microbiol. Biotechnol. 88, 1243-1251.

Shiao, M.-S., 2003. Natural products of the medicinal fungus Ganoderma lucidum: occurrence, biological activities, and pharmacological functions. Chem. Rec. 3, $172-180$.

Shuman Moss, L.A., Jensen-Taubman, S., Stetler-Stevenson, W.G., 2012. Matrix metalloproteinases: changing roles in tumor progression and metastasis. Am. J. Pathol. 181, 1895-1899.

Sliva, D., 2003. Ganoderma lucidum (Reishi) in cancer treatment. Integr. Cancer Ther. 2, 358-364.

Sliva, D., Loganathan, J., Jiang, J., Jedinak, A., Lamb, J.G., Terry, C., Baldridge, L.A., Adamec, J., Sandusky, G.E., Dudhgaonkar, S., 2012. Mushroom Ganoderma lucidum prevents colitis-associated carcinogenesis in mice. PLoS ONE 7, e47873.

Smina, T.P., De, S., Devasagayam, T.P., Adhikari, S., Janardhanan, K.K., 2011. Ganoderma lucidum total triterpenes prevent radiation-induced DNA damage and apoptosis in splenic lymphocytes in vitro. Mutat. Res. 726, 188-194.

Sparks, N.H.C., 2006. The hen's egg - is its role in human nutrition changing? World's Poult. Sci. J. 62, 308-315.

Stojković, D.B., Calhelha, L., Glamočlija, R.C., Ćirić, J., van Griensven, A., Soković, L.J.L.D., Ferreira, I.C.F.R., 2014. A detailed comparative study between chemical and bioactive properties of Ganoderma lucidum from different origins. Int. J. Food Sci. Nutr. 65, 42-47.

Stuart, G.A., 1911. Chinese Materia Medica: Vegetable Kingdom. Extensively revised from F. Porter Smith's Work by G. A. Stuart. American Presbyterian Mission Press,

Sun, L.X., Lin, Z.B., Li, X.J., Li, M., Lu, J., Duan, X.S., Ge, Z.H., Song, Y.X., Xing, E.H., Li, W.D., 2011. Promoting effects of Ganoderma lucidum polysaccharides on B16F10 cells to activate lymphocytes. Basic Clin. Pharmacol. Toxicol. 108, 149-154.

Sun, X., Wang, H., Han, X., Chen, S., Zhu, S., Dai, J., 2014. Fingerprint analysis of polysaccharides from different Ganoderma by HPLC combined with chemometrics methods. Carbohydr. Polym. 114, 432-439.

Tang, W., Liu, J.W., Zhao, W.M., Wei, D.Z., Zhong, J.J., 2006. Ganoderic acid T from Ganoderma lucidum mycelia induces mitochondria mediated apoptosis in lung cancer cells. Life Sci. 80, 205-211.

Teekachunhatean, S.S., Sadja, S., Ampasavate, C., Chiranthanut, N., Rojanasthien, N., Sangdee, C., 2012. Pharmacokinetics of ganoderic acids A and F after oral administration of Ling Zhi preparation in healthy male volunteers. Evid-Based Compl. Alt. 2012, 780892.

Thyagarajan, A., Jedinak, A., Nguyen, H., Terry, C., Baldridge, L.A., Jiang, J., Sliva, D., 2010. Triterpenes from Ganoderma lucidum induce autophagy in colon cancer through the inhibition of p38 mitogen-activated kinase (p38 MAPK). Nutr. Cancer 62, 630-640.

U.S. Food and Drug Administration, 2010. Title 21 - Food And Drugs. US Government.

Upton, R., 2000. Reishi Mushroom: Ganoderma lucidum: Standards of Analysis, Quality Control, and Therapeutics. Am. Herb. Pharmacop.

Wachtel-Galor, S., Yuen, J., Buswell, J.A., Benzie, I.F.F., 2011. Ganoderma lucidum (Lingzhi or Reishi): A Medicinal Mushroom. Taylor and Francis Group.
Wan, M.C.K., 2007. Jiajing emperor and his auspicious words. Arch. Asian Art 57, 95-120.

Wang, D.M., Wu, S.H., Su, C.H., Peng, J.T., Shih, Y.H., Chen, L.C., 2009. Ganoderma multipileum, the correct name for 'G. lucidum' in tropical Asia. Bot. Stud. 50, 451458.

Wang, G., Zhao, J., Liu, J., Huang, Y., Zhong, J.J., Tang, W., 2007. Enhancement of IL-2 and IFN-gamma expression and NK cells activity involved in the anti-tumor effect of ganoderic acid Me in vivo. Int. Immunopharmacol. 7, 864-870.

Wang, H.X., Ng, T.B., 2006. A laccase from the medicinal mushroom Ganoderma lucidum. Appl. Microbiol. Biotechnol. 72, 508-513.

Wang, J.L., Gu, T., Zhong, J.J., 2012a. Enhanced recovery of antitumor ganoderic acid T from Ganoderma lucidum mycelia by novel chemical conversion strategy. Biotechnol. Bioeng. 109, 754-762.

Wang, X.-C., Xi, R.-J., Li, Y., Wang, D.-M., Yao, Y.-J., 2012b. The species identity of the widely cultivated ganoderma, 'G. lucidum' (Ling-zhi), in China. PLoS ONE 7, 112.

Wasser, S., 2011. Current findings, future trends, and unsolved problems in studies of medicinal mushrooms. Appl. Microbiol. Biotechnol. 89, 1323-1332.

WHO, 2014. Press Release 224. International Agency for Research on Cancer.

Williams, N.M., 2007. A conversation in poems: Xie Lingyun, Xie Huilian, and Jiang Yan. J. Am. Orient. Soc. 127, 491-506.

Wilson, J.K., 1994. The Fine Art of Drinking: The Chinese Silversmith Zhu Bishan and His Sculptural Cups. B. Cleveland Mus. Art 81, 380-401.

Wu, G., Qian, Z., Guo, J., Hu, D., Bao, J., Xie, J., Xu, W., Lu, J., Chen, X., Wang, Y., 2012 Ganoderma lucidum extract induces G1 cell cycle arrest, and apoptosis in human breast cancer cells. Am. J. Chin. Med. 40, 631-642.

Wu, G.S., Guo, J.J., Bao, J.L., Li, X.W., Chen, X.P., Lu, J.J., Wang, Y.T., 2013. Anti-cancer properties of triterpenoids isolated from Ganoderma lucidum - a review. Expert Opin. Investig. Drugs 22, 981-992.

Xu, J.W., Xu, Y.N., Zhong, J.J., 2012. Enhancement of ganoderic acid accumulation by overexpression of an N-terminally truncated 3-hydroxy-3-methylglutary coenzyme A reductase gene in the basidiomycete Ganoderma lucidum. Appl. Environ. Microbiol. 78, 7968-7976.

Xu, J.W., Zhao, W., Zhong, J.J., 2010. Biotechnological production and application of ganoderic acids. Appl. Microbiol. Biotechnol. 87, 457-466.

Xu, Y.-N., Xia, X.-X., Zhong, J.-J., 2014. Induction of ganoderic acid biosynthesis by $\mathrm{Mn}^{2+}$ in static liquid cultivation of Ganoderma lucidum. Biotechnol. Bioeng. 111, 2358-2365.

Xu, Y.N., Xia, X.X., Zhong, J.J., 2013. Induced effect of $\mathrm{Na}(+)$ on ganoderic acid biosynthesis in static liquid culture of Ganoderma lucidum via calcineurin signal transduction. Biotechnol. Bioeng. 110, 1913-1923.

Xu, Y.N., Zhong, J.J., 2012. Impacts of calcium signal transduction on the fermentation production of antitumor ganoderic acids by medicinal mushroom Ganoderma lucidum. Biotechnol. Adv. 30, 1301-1308.

Yang, S., 1998. The Divine Farmer's Materia Medica: A Translation of the Shen Nong Ben Cao Jing. Blue Poppy Press.

Ye, L., Li, J., Zhang, J., Pan, Y., 2010. NMR characterization for polysaccharide moiety of a glycopeptide. Fitoterapia 81, 93-96.

Yue, G.F., Tse, K.-P., Leung, G.M.K., Lau, C.B.S., 2006. Comparative studies of various Ganoderma species and their different parts with regard to their antitumor and immunomodulating activities in vitro. J. Altern. Complem. Med. 12, $777-$ 789.

Yue, Q.X., Song, X.Y., Ma, C., Feng, L.X., Guan, S.H., Wu, W.Y., Yang, M., Jiang, B.H., Liu, X., Cui, Y.J., Guo, D.A., 2010. Effects of triterpenes from Ganoderma lucidum on protein expression profile of HeLa cells. Phytomedicine 17, 606-613.

Zhang, Q., Zuo, F., Nakamura, N., Ma, C.-M., Hattori, M., 2009. Metabolism and pharmacokinetics in rats of ganoderiol $\mathrm{F}$, a highly cytotoxic and antitumor triterpene from Ganoderma lucidum. J. Nat. Med. 63, 304-310.

Zhang, X.Q., Ip, F.C., Zhang, D.M., Chen, L.X., Zhang, W., Li, Y.L., Ip, N.Y., Ye, W.C. 2011. Triterpenoids with neurotrophic activity from Ganoderma lucidum. Nat Prod. Res. 25, 1607-1613.

Zhao, H., Zhang, Q., Zhao, L., Huang, X., Wang, J., Kang, X., 2012. Spore powder of Ganoderma lucidum improves cancer-related fatigue in breast cancer patients undergoing endocrine therapy: a pilot clinical trial. Evid. Based Complem. Altern. Med. 2012, 809614.

Zhao, S., Ye, G., Fu, G., Cheng, J.-X., Yang, B.B., Peng, C., 2011. Ganoderma lucidum exerts anti-tumor effects on ovarian cancer cells and enhances their sensitivity to cisplatin. Int. J. Oncol. 38, 1319-1327.

Zhong, J.J., Tang, Y.J., 2004. Submerged cultivation of medicinal mushrooms for production of valuable bioactive metabolites. Adv. Biochem. Eng. Biotechnol. 87, 25-59.

Zhou, L.-W., Cao, Y., Wub, S.-H., Vlasák, J., Li, D.-W., Li, M.-J., Dai, Y.-C., 2015 Global diversity of the Ganoderma lucidum complex (Ganodermataceae Polyporales) inferred from morphology and multilocus phylogeny. Phytochemistry 114, 7-15.

Zhou, Y., Qu, Z.Q., Zeng, Y.S., Lin, Y.K., Li, Y., Chung, P., Wong, R., Hagg, U., 2012 Neuroprotective effect of preadministration with Ganoderma lucidum spore on rat hippocampus. Exp. Toxicol. Pathol. 64, 673-680.

Zong, W.X., Li, C., Hatzivassiliou, G., Lindsten, T., Yu, Q.C., Yuan, J., Thompson, C.B., 2003. Bax and Bak can localize to the endoplasmic reticulum to initiate apoptosis. J. Cell Biol. 162, 59-69. 


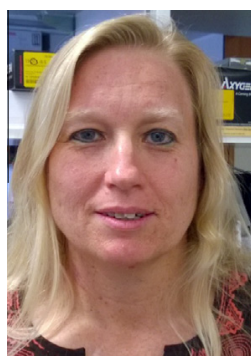

Karen Bishop obtained her $\mathrm{PhD}$ at the University of Natal, South Africa. The focus of her dissertation was multidrug resistance in Mycobaterium tuberculosis. Since that time she has worked on drug resistance and vaccine design in HIV, and in 2010 joined the Auckland Cancer Society Research Centre at the University of Auckland where she started work on prostate cancer and the interaction between genotype and diet. This interest has led to various genotyping studies, a dietary intervention study in men with Prostate cancer as well as involvement in in vitro studies using extracts of Lingzhi.

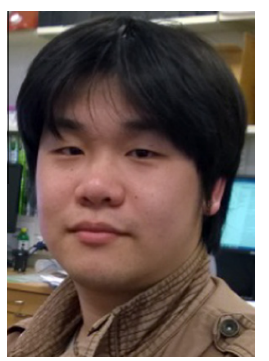

Chi Hsiu-Juei (Ben) Kao is a PhD candidate in the Discipline of Nutrition, Faculty of Medical and Health Science, University of Auckland, New Zealand. His Masters of Health Science (2013) thesis was on anticancer activity of Lingzhi/Ganoderma extracts. The focus of Ben's PhD is Lingzhi/Ganoderma and its use as an anticancer agent. Ben wishes to connect ancient medicine to modern day science using molecular tools.

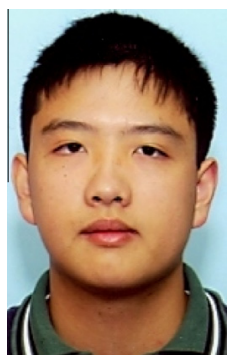

Yuanye Xu is a medical student at the University of Auckland and has recently completed his fourth year of studies towards his MBChB degree. He worked with the authors during a Summer studentship held at the Department of Nutrition at the Faculty of Medical and Health Sciences at the University of Auckland earlier this year. He is currently interested in pursuing a career in oncology.

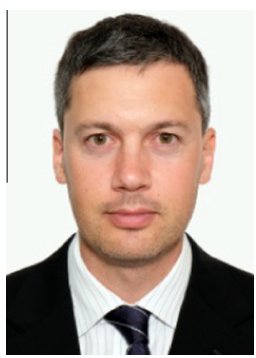

Marcus Glucina is the CEO and Director of NZ FOCUS based in Hong Kong. NZ Focus is supporting the ongoing research with supplies of wild Lynzhi and other materials. A former graduate of Auckland University with a Bcom/LLB, Marcus and his team are working with a number of Lynzhi based products in North Asia.

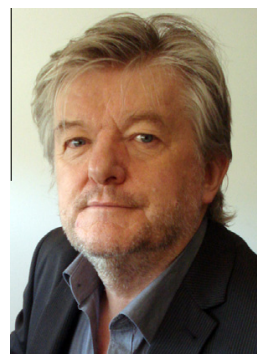

Russell Paterson has a BSc Honours in Applied Microbiology from the University of Strathclyde, UK. His MSc and PhD were in Chemistry from the University of Manchester, UK, under the supervision of J. D. BúLock, of fungal secondary metabolism fame. He undertook a 2.5 year postdoctoral appointment at the Boyce Thompson Institute at Cornell University, New York, USA. Dr Paterson worked at the Centre for Industrial Innovation, Strathclyde University for 2 years before being employed at the international non-governmental organization, CABI, UK where he was the Senior Scientist researching Fungal Natural Products. He was awarded the IOI Professorial Chair in Plant Pathology at the Universiti Putra Malaysia, Malaysia in 2008. Currently, he is employed as a researcher at the Centre for Biological Engineering, University of Minho, Portugal. Russell has worked in many countries particularly in S. E. Asia and was central to a fungal bioprospecting project in the Iwokrama rain forest of Guyana. The European Research Council confirmed that he is appointed as an External Reviewer of Projects (2012, 2013). Editorial roles have included coordinating editor of Mycopathologia, and he is an editor of Current Enzyme Inhibition, Journal of Earth Science \& Climatic Change, and Current Opinion in Food Science. He has written numerous papers, books and chapters on aspects of fungal secondary metabolism. This Special Issue was inspired by his 2006 review of Ganoderma published in Phytochemistry, which has been cited c. 290 times (Scopus) and is his highest cited paper: It was the inspiration for this Special Issue on the topic. He has a total publication list of c. 200.

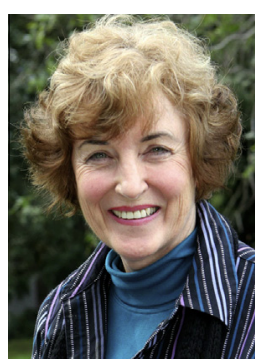

Lynn Ferguson obtained her D.Phil. from Oxford University, working on the subject of DNA damage, DNA repair and mutagenesis in yeast. After her return to New Zealand, she began working as part of the Auckland Cancer Society Research Centre, using mutagenicity testing as a predictor of carcinogenesis, with particular focus on the New Zealand situation. In 2000, she took on a $50 \%$ role as Head of a new Discipline of Nutrition at The University of Auckland. In more recent years, she has considered the interplay between genes and diet in the development of chronic disease, with particular focus on Inflammatory Bowel Disease, a cancer-prone condition, and also in prostate cancer. As programme leader for the multidisciplinary-multiorganisation Nutrigenomics New Zealand, she has been working with a range of others to bring nutrigenomics tools and potential to the New Zealand science scene. She has supervised more than 30 students to the successful completion of B.tech, MSc or PhD. Her laboratory regularly supervises 2-3 summer students each year. She is the author or co-author of more than 350 peer reviewed publications as chapters in books or articles in international journals. Her current H-index (Google Scholar) is 48, with 9334 citations. She serves on the Editorial Boards of several major journals. 